\title{
Association of dry eye disease with psychiatric or neurological disorders in elderly patients
}

This article was published in the following Dove Press journal:

Clinical Interventions in Aging

15 May 2017

Number of times this article has been viewed

\section{Sang Beom Han' \\ Hee Kyung Yang ${ }^{2}$ \\ Joon Young Hyon ${ }^{2}$ \\ Won Ryang Wee ${ }^{3}$}

'Department of Ophthalmology, Kangwon National University Hospital, Chuncheon, Gangwon, ${ }^{2}$ Department of Ophthalmology, Seoul National University Bundang Hospital, Seongnam, Gyeonggi, ${ }^{3}$ Department of Ophthalmology, Seoul National University Hospital, Seoul, Republic of Korea
Correspondence: Joon Young Hyon Department of Ophthalmology, Seoul National University Bundang Hospital, 300 Gumi-dong, Bundang-gu, Seongnam, Gyeonggi 463-707, Republic of Korea

Tel +82 3। 7877379

Fax +82 31 7874057

Email jyhyon@snu.ac.kr

\begin{abstract}
Dry eye disease (DED) is a common disease that can impair quality of life significantly. Its prevalence increases with advancing age, and the economic burden of the disease on both a patient and the society is increasing with elongation of life expectancy. The diagnosis and treatment of DED are often difficult due to the discordance between symptoms and signs of the disease. Recent studies have suggested the role of neurological or psychological factors in the development of dry eye symptoms and discrepancy of the symptoms and signs, particularly in elderly patients. In this review, the authors discuss the association of DED with various psychiatric and neurological disorders. In addition to psychiatric conditions, including depression, anxiety, stress, posttraumatic stress disorder and sleep disorders, medications for the psychiatric disorders have association with DED. Neurological disorders, such as neuropathic pain, chronic pain syndrome, peripheral neuropathy and several central nervous system disorders, are related to DED. Treatment of DED, combined with psychiatric or neurological disorders, is also discussed. Attention should be paid to the DED patients with discordant symptoms and signs, and unsatisfactory response to conventional treatment for associated psychiatric or neurological disorders, as well as an integrated treatment approach, could be helpful for these patients.
\end{abstract}

Keywords: depression, dry eye disease, neurological disorder, neuropathic pain, psychiatric disorders, sleep disorder

\section{Introduction}

Dry eye disease (DED) is one of the most common ophthalmologic disorders. ${ }^{1}$ It is associated with symptoms including ocular discomfort, pain, dryness and foreign body sensation, which can impair the quality of life of millions of people worldwide. ${ }^{1}$ In terms of economic burden, DED has become a major public health problem. ${ }^{2}$ DED poses an average cost of $\$ 11,302$ per patient and an estimated overall cost of $\$ 55.4$ billion to the US society annually. ${ }^{3}$

DED becomes more prevalent with increasing age. ${ }^{4-6}$ In a male population aged $\geq 50$ years in the US, the prevalence of DED increased with age, from $3.90 \%$ among men of 50-54 years of age to $7.67 \%$ among men $\geq 80$ years of age. ${ }^{7}$ Similarly, among adult US women, DED prevalence increased from $5.7 \%$ in a group $<50$ years of age to $9.8 \%$ in a group $\geq 75$ years of age. ${ }^{8}$ The prevalence of DED in an adult population of age $\geq 50$ years in the US was reported to be $4.34 \%$, or 1.68 million, among males, and $7.8 \%$, or 3.23 million, among female subjects. ${ }^{7,8}$ Our previous study revealed that the prevalence of DED in an elderly Korean population of age $\geq 65$ years was $33.2 \% .{ }^{9}$ Thus, with elongation of life expectancy, the economic burden of DED on both a patient and the society is expected to be increasing, ${ }^{10}$ which underscores the importance of the understanding of the pathogenesis of and development of effective treatment methods for DED in elderly patients. 
As the International Dry Eye Workshop in 2007 defined the DED as a multifactorial disease, ${ }^{11}$ DED represents a heterogeneous collection of clinical disorders caused by various pathophysiological etiologies. ${ }^{12,13}$ Disparity between common dry eye symptoms and signs has been reported, which makes the diagnosis and treatment of DED difficult., ${ }^{9,14}$ Although this discrepancy can partly be explained by the limited reliability of the dry eye tests currently available; individual differences in cognitive response to dry eye questionnaires, ${ }^{9}$ the heterogeneous nature of DED and individual variability in the perception of dry eye symptoms may also play an important role. ${ }^{9}$ In particular, studies focused on the association of DED with neurological or psychiatric disorders have suggested the role of neurological or psychological factors in the development of dry eye symptoms, particularly in elderly patients. ${ }^{2,12,17-21}$ Vehof et al ${ }^{17}$ recently showed that severe dry eye symptoms unproportional to external signs were associated with lower level of self-perceived health. Shtein et $\mathrm{a}^{22}$ revealed that DED patients with discordant symptoms and signs had reduced corneal nerve density and lower visual quality-of-life scores, suggesting the presence of central neurological pathophysiology modulating the ocular symptoms. A study by Galor et a $1^{12}$ on US veterans with mean age of 65 years also demonstrated that dry eye symptoms were more closely related to depression and posttraumatic stress disorder (PTSD) than tear film parameters, suggesting an association between DED and psychiatric disorders.

In this review, we aim to provide an overview of the association between DED and neurological or psychiatric disorders, in addition to discussing the underlying pathophysiological mechanisms and treatment methods for dry eye symptoms combined with psychiatric or neurological disorders.

\section{Association with psychiatric problems \\ Depression, anxiety, stress and PTSD}

Population-based studies have shown the association of DED with depression, anxiety and stress. ${ }^{19,23-25}$ In a study on elderly Koreans of age 65 years or older, Kim et al ${ }^{19}$ revealed that depression was related to dry eye symptoms in patients with normal or mildly reduced tear production. In a large population-based study including 6,655 women of $\geq 19$ years of age, $\mathrm{Na}$ et $\mathrm{al}^{25}$ revealed that subjects with DED showed increased risk of experiencing severe psychological stress, anxiety and depression. Yilmaz et $\mathrm{al}^{26}$ also reported that subjects with depression, stress and anxiety are more prone to DED.
Studies on US veteran populations also indicated an association of DED with depression and PTSD, which was suggested to be caused by shared pathophysiology or medications prescribed for psychiatric diseases. ${ }^{5,6,27}$ Szakats et $\mathrm{al}^{28}$ demonstrated that the scores of the psychological questionnaires, including Shortened Health Anxiety Inventory, Shortened Beck Depression Inventory and Beck Anxiety Inventory, had significant correlation with the ocular surface disease index score, whereas there was no significant correlation between dry eye signs and symptoms. Hallak et $\mathrm{al}^{29}$ revealed that depressive symptoms scored using the Beck Depression Inventory showed significant association with dry eye symptom scores. These findings suggest that health anxiety, depression and anxiety may affect the development of dry eye symptoms and may be one of the causes of the inconsistency between symptoms and signs of DED. ${ }^{28,29}$ $\mathrm{Nepp}^{30}$ showed that patients with DED recalcitrant to treatment often have anxiety and depression and also postulated that the psychological status influenced the nervous system to suppress tear secretion from the lacrimal gland..$^{30}$

A meta-analysis demonstrated that DED was associated with higher symptom scores of anxiety and depression, as well as with an increased prevalence of the psychiatric conditions. ${ }^{31}$ Among the DED patients, the severity and prevalence of depression were greatest among patients with primary Sjogren's syndrome (SS). ${ }^{31}$ A study on Chinese women with SS with mean age of 49.8 years also revealed that SS was related to higher scores on the Self-Rating Anxiety and Depression Scales and to increased prevalence of anxiety and depression. ${ }^{32}$ In these patients, the depression and anxiety scores were negatively correlated with visionrelated quality of life. ${ }^{32}$

Regarding the association between DED and depression, several mechanisms may play a role. ${ }^{19}$ Common risk factors, such as female sex, menopause and an increased omega-6: omega- 3 ratio, shared by the two diseases suggest an overlap in the pathogenesis. ${ }^{19,33}$ Moreover, chronic depression may worsen dry eye symptoms by promoting production of proinflammatory cytokines. ${ }^{19,34}$ Depressive mood can also lower the threshold for perception of discomfort or pain caused by DED by affecting cognitive modulation of attention. ${ }^{35}$ Somatization, a frequently reported condition in depression, may predispose to development of dry eye symptoms. ${ }^{19}$ Conversely, dry eye symptoms including chronic discomfort and visual impairment can also worsen depressive mood. ${ }^{19}$ Visual blurring induced by tear film instability was suggested to predispose DED patients to depressive tendency. ${ }^{36} \mathrm{Li}$ et al ${ }^{37}$ also showed that impairment of vision-related 
quality of life in patients with DED can aggravate depression and anxiety. ${ }^{37}$ The need for frequent instillations of artificial tears can also affect social interactions and aggravate psychological stress and depression. ${ }^{1}$

Genetically, single-nucleotide polymorphisms in the genes encoding receptors for brain-derived neurotrophic factor and vitamin $\mathrm{D}$ were reported to be potentially related to DED. ${ }^{38} \mathrm{~A}$ remarkable finding is that depression status may influence the association between DED and Val66Met single-nucleotide polymorphism in brain-derived neurotrophic factor. ${ }^{38}$

\section{Sleep disorders}

The results of several previous research works suggest a reciprocal relationship between DED and sleep disorders, particularly in elderly patients. ${ }^{18,39-43}$ A cross-sectional study including 187 veterans with mean age of 63 years demonstrated that the severity of dry eye symptoms was closely aligned with that of insomnia. ${ }^{18}$ In a study in which quality of sleep was quantified using the Pittsburgh Sleep Quality Index (PSQI), severity of DED had significant correlation with PSQI. ${ }^{39}$ Another remarkable finding is that the PSQI score in DED patients was significantly lower than in those with other ocular surface diseases. ${ }^{39}$

A research using the Taiwan National Health Insurance Research Database showed that patients with primary SS had increased risk for sleep disorder, as well as depression and anxiety, compared with those without SS. ${ }^{42}$ Priori et $\mathrm{al}^{41}$ also revealed that patients with primary SS had impaired sleep quality measured using PSQI, especially lower scores for perceived sleep quality and daily disturbances. ${ }^{41}$

Sleep deprivation may also be associated with increased risk of DED. ${ }^{43,44}$ A large population-based study in Korea revealed that short sleep duration of $\leq 5$ hours/day was related to higher prevalence of DED. ${ }^{43}$ An experimental study on human subjects demonstrated that sleep deprivation led to increased tear osmolarity, decreased tear secretion and shortened tear film breakup time, all of which can aggravate the symptoms and signs of DED. ${ }^{44}$

Ayaki et $\mathrm{al}^{40}$ revealed that topical treatment with eye drops significantly improved PSQI in patients with DED, and the improvement was greater in newly diagnosed DED compared to established DED, suggesting that DED may also influence sleep disorder and that early treatment of DED can also improve sleep quality. They also reported that combination of sleep services and topical treatment with eye drops could successfully treat patients with sleep disorders overlapped with DED. ${ }^{40}$

\section{Medications for psychiatric disorders}

Previous studies indicated that medications prescribed for psychiatric conditions may precipitate DED. ${ }^{5,6,45}$ Most of the antidepressant drugs, such as tricyclic antidepressants (TCAs), selective serotonin reuptake inhibitors (SSRIs) or serotonin-norepinephrine reuptake inhibitors (SNRIs) have antagonistic effects on muscarinic receptors, which can cause adverse effects, including DED, dry mouth and constipation. ${ }^{46}$ Theoretically, SSRIs have weaker anticholinergic effects than TCAs, and dry mouth was less frequently observed in SSRI users than in TCAs users. ${ }^{47,48}$ However, regarding DED, there has been no established guidelines for antidepressant use, ${ }^{46}$ which can be, at least in part, explained by the differences in sensitivities of various glands to the antimuscarinic effect. ${ }^{46}$

Clinically, several studies have revealed that SSRIs are associated with an increased risk of DED. ${ }^{49-51}$ A study on 248 elderly male veterans of age 50 years or older revealed that use of SSRIs was significantly associated with severe dry eye symptoms. ${ }^{49}$ In a study on 472 Chinese patients with psychiatric diseases, including depression, anxiety disorder, obsessive-compulsive disorder and panic disorder, subjects using SSRIs showed significantly higher risk of DED compared to those on no medication or using other types of psychiatric medication..$^{50}$ Kocer et a ${ }^{51}$ also reported that both SNRIs and SSRIs were related to increased risk for DED and suggested the presence of another mechanism rather than the anticholinergic effect. ${ }^{51}$ One plausible explanation is that SSRIs can alter the tear serotonin level, which can in turn influence the sensitivity thresholds of corneal nerve sensitivity. ${ }^{45}$

Most antipsychotics for schizophrenia and some drugs for Parkinson's disease, including dopamine and levodopa, also have anticholinergic effects. ${ }^{46}$ As the symptoms of schizophrenia, including avolition and alogia, and those of Parkinson's disease, including poor blinking response, can be major challenges in the diagnosis and treatment of DED, care should be taken for patients using these medications. ${ }^{46}$ There is also a report that lithium carbonate and sodium valproate prescribed for bipolar disorder were associated with decreased tear film breakup time, which can cause DED. ${ }^{52}$

\section{Association with neurological problems Neuropathic pain}

Neuropathic pain is defined as "pain caused by a lesion or disease of the somatosensory system" 53 and is assumed to be a pathological manifestation of peripheral and central 
sensitization, promoted by peripheral nerve injury, leading to maladaptive neuroplastic changes in components of both the peripheral and central nervous systems (PNS and CNS) of the sensory processing pathway. ${ }^{54,55}$ A subgroup of DED is characterized by discrepancy between signs and symptoms of dry eye and shows the features of neuropathic pain, including dysesthesia (unpleasant abnormal sensations), spontaneous pain, allodynia (pain response to innoxious stimuli including light and wind) and hyperalgesia (exaggerated pain to noxious stimuli). ${ }^{2,13,21}$ Persistent ocular neuropathic pain may develop associated with repeated sensory nerve injury or inflammation, which leads to chronic changes in the peripheral and central somatosensory pathway, even after the resolution of initial insults, including tear dysfunction or ocular surface damage. ${ }^{2,56}$

Peripheral sensitization involves alteration of corneal nociceptors from noxious stimuli detectors to innoxious stimuli sensors. ${ }^{56}$ Acute axonal injury during corneal nerve damage facilitates the release of inflammatory mediators, including prostaglandins, cytokines such as interleukin-1 and tumor necrosis factor- $\alpha$, and neuropeptides such as substance $\mathrm{P}$, which can reduce the threshold potentials of ion channels of corneal nerve endings. ${ }^{56}$ Subsequent release of nerve growth factor leads to upregulation and expression of genes, resulting in hypersensitivity of corneal nociceptors to stimuli. ${ }^{2,56}$ In addition, chronic severe or repeated axonal injury promotes the transition of the function of corneal nociceptors from signal transmission to nerve regeneration. ${ }^{2}$ With regeneration, the injured nerve can develop microneuromas, endobulbs and nerve sprouts, which can be sources of spontaneous pain. ${ }^{2,56}$ The alteration of corneal nerves after laser in situ keratomileusis (LASIK) resembles the pathological neuroplasticity in peripheral sensitization ${ }^{57}$ and is assumed to be the most likely cause of the dry eye symptoms after LASIK. ${ }^{58}$

Central sensitization can develop as a result of persistent activation of nociceptors and progression of peripheral sensitization. ${ }^{2,56}$ Persistent activity of corneal nociceptors promotes glutamate release from presynaptic afferent neurons, which leads to activation of $N$-methyl-D-aspartic acid (NMDA) receptors. ${ }^{54,56}$ Subsequently, sodium channels of second-order pain-signaling neurons in the trigeminal subnucleus caudalis (TSNC) are activated even with innoxious or weakly noxious stimuli, resulting in central sensitization. ${ }^{54,56}$ Results of an in vitro study showing that NMDA receptors mediate the interaction between TSNC and corneal epithelial cells support this assumption. ${ }^{59}$ Moreover, inflammatory response to a noxious insult decreases the normally present inhibitory effect of $\gamma$-aminobutyric acid (GABA) on the ascending pain pathway, which contributes to chronic neuropathic pain. ${ }^{2}$

A study on 102 male veterans of age 50 years or older revealed that severity and persistence of dry eye symptoms were associated with symptoms of neuropathic ocular pain, suggesting the involvement of neuropathic mechanisms. ${ }^{60}$ In a study on 129 veterans with mean age 64 years, mechanical detection and pain thresholds on the cornea were closely aligned with dry eye symptoms and neuropathic ocular pain, suggesting the hypersensitivity within the corneal somatosensory pathways in patients with more severe dry eye symptoms. ${ }^{61}$ Insufficient response to artificial tears was also associated with features of neuropathic ocular pain. ${ }^{62}$ Neuropathic ocular pain severity correlates with pain sensitivity at forearm, suggesting the involvement of central somatosensory dysfunction in neuropathic-like dry eye symptom. ${ }^{63}$ Patients with persistent ocular pain and dry eye symptoms after topical proparacaine instillation also had greater sensitivity of the forearm and forehead, which is an evidence of central sensitization. ${ }^{64}$

\section{Chronic pain syndrome (CPS)}

The association of DED with CPS has been suggested. ${ }^{13,65-67}$ Vehof et $\mathrm{a}^{67}$ showed a close relationship between DED and chronic widespread pain syndrome. A study including 154 veterans revealed that DED patients with more frequent manifestation of CPS reported more severe dry eye symptoms and neuropathic ocular pain score, suggesting shared pathogenesis between some subtypes of DED and CPS. Crane et $\mathrm{l}^{65}$ also reported that DED patients with worse neuropathic ocular pain symptoms showed more severe comorbid chronic pain disorders. A recent study including a large cohort of twins with mean age of 54.7 years presented evidence of shared genetic factors between chronic widespread pain and DED. ${ }^{66}$

\section{Peripheral neuropathy (PN)}

Diabetic PN is often associated with DED. ${ }^{68}$ Diabetic PN was shown to be associated with decrease in corneal nerve fiber density, which can lead to reduced corneal sensitivity. ${ }^{69}$ Misra et $\mathrm{al}^{70}$ reported significant impairment of tear film stability and lipid layer quality in patients with diabetes mellitus. The severity of diabetic PN is closely aligned with the severity of dry eye signs, including tear film parameters. ${ }^{70,71}$ However, due to corneal hypoesthesia associated with diabetic $\mathrm{PN}$, patients are often asymptomatic even in the presence of serious ocular surface damage. ${ }^{71}$ Thus, periodic screening of the ocular 
surface and the retina is necessary for patients with diabetes mellitus for early detection and treatment of DED. ${ }^{68,71}$

In patients with SS, inconsistency of signs and symptoms of dry eye with the degree of autoimmune activity is often observed. ${ }^{72}$ In the early stages, dry eye symptoms often develop in the absence of ocular surface damage or decreased tear production, possibly due to corneal sensitization. ${ }^{73}$ The findings that $\mathrm{PN}$ often develops in patients with primary SS support the assumption. ${ }^{74}$ Han et $\mathrm{al}^{75}$ demonstrated that patients with primary SS showed reduced corneal sensitivity in the presence of more severe dry eye signs compared to those with non-SS DED, which can contribute to the discordance between signs and symptoms of dry eye. Villani et $\mathrm{al}^{76}$ reported that $\mathrm{SS}$ induces more severe neurotrophic keratitis than non-SS dry eye by causing more damage to the subbasal nerve plexus.

\section{CNS manifestations}

In addition to DED and PN, CNS manifestations are also frequently reported in $\mathrm{SS}^{77}$ Morreale et $\mathrm{al}^{77}$ revealed that headache, cognition and mood disorders in patients with SS were significantly associated with serological markers of SS, suggesting the possible role of inflammation-mediated cerebral microcirculation dysfunction. ${ }^{77}$

Association between chronic migraine and DED was also suggested. ${ }^{78}$ In vivo confocal microscopy showed significantly decreased corneal nerve fiber density in migraine patients, and all the patients with migraine had dry eye symptoms..$^{78}$ A large population-based study in Korea also revealed that patients with migraine had significantly higher risk of DED. ${ }^{79}$

Borsook and Rosenthal ${ }^{80}$ reported five cases of patients with chronic neuropathic ocular pain accompanied with blepharospasm associated with objective changes in the nerve plexus, suggesting the potential involvement of the basal ganglia in both conditions.

\section{Management}

Discordance between dry eye signs and symptoms and unsatisfactory response to conventional topical treatment should prompt consideration of the influence of psychological or neurological factors. ${ }^{21}$ Treatment of accompanying psychiatric or neurological problems can be helpful in alleviating dry eye symptoms. Considering the reciprocal influence between DED and psychiatric disorders, comprehensive management of both conditions would be more beneficial. ${ }^{40,81}$

For neuropathic pain, considering that pain can become spontaneous and unresponsive to artificial tear instillation once central sensitization develops, limitation of the neuroplastic sensitization process by prevention of ocular surface damage and inflammation in the initial stages would be important. ${ }^{2,21,56,82}$ Aggressive treatment with anti-inflammatory medications is necessary for relief of acute pain and improvement of ocular surface inflammation. ${ }^{56,82}$ Topical nonsteroidal anti-inflammatory drugs (NSAIDs) can be helpful for pain relief and prevention of peripheral and central sensitization, ${ }^{2}$ among which diclofenac may have an additional effect of prevention of the neuroplastic process as it reduces neuronal excitability by opening neuronal potassium channels. ${ }^{83}$ Topical steroids, cyclosporine A and tacrolimus are also useful for reducing ocular surface inflammation. ${ }^{2}$ Inhibitors of matrix metalloproteinases, such as oral doxycycline and topical azithromycin, also have anti-inflammatory effects and inhibit proinflammatory cytokines, and so these are expected to reduce the chronic inflammation. ${ }^{2}$ Topical opioid is also suggested to be effective in alleviating acute ocular pain and attenuating subsequent peripheral and central sensitization. ${ }^{2,84,85}$ Topical application of autologous serum, umbilical cord serum and platelet-rich plasma was also shown to be effective in facilitating corneal nerve regeneration and epithelial healing. ${ }^{56}$

Systemic pharmacotherapy used for chronic pain management can be effective for central neuropathic pain. ${ }^{56}$ Pregabalin and gabapentin, developed and used as antiepileptic drugs, are now often prescribed as the first-line medications for central neuropathic pain. ${ }^{86}$ TCAs, such as desipramine and nortriptyline, are often considered as the first-line treatment for neuropathic pain. ${ }^{56,86}$ Efficacy of TCAs in alleviating dry eye symptoms after LASIK has also been reported. ${ }^{48}$ SNRIs, including venlafaxine and duloxetine, and opioids including tramadol were also proven to be effective for neuropathic pain. ${ }^{86}$

Supplementation with omega- 3 fatty acids was proven to reduce inflammation both in the ocular surface and CNS, which may improve both DED and psychiatric conditions, including depression, stress and anxiety. ${ }^{33,87}$ Anecdotal evidence showed that topical or parenteral supplementation with cobalamin (vitamin B12) was effective in restoring corneal sensitivity and improving corneal neuropathic pain recalcitrant to conventional topical treatment. ${ }^{88,89}$ Electrical stimulation of the trigeminal ganglion and intrathecal targeted delivery of drugs, including bupivacaine and fentanyl, were also introduced as potentially effective options for recalcitrant corneal neuropathic pain. ${ }^{90,91}$ Prosthetic replacement of the ocular surface ecosystem (PROSE) treatment was also suggested to be effective for the management of DED and 
corneal neuralgia after LASIK. ${ }^{92}$ Further studies are required for development of treatment modalities targeted at various neuroplastic sensitization processes that lead to chronic neuropathy-like dry eye symptoms. ${ }^{2,82}$

\section{Conclusion}

DED is a multifactorial disease and is often associated with various psychological or neurological conditions. Psychiatric disorders, such as depression, anxiety, stress, PTSD and sleep disorders, are related to DED. Medications for psychiatric disorders also can influence DED. Neurological disorders, including neuropathic pain, chronic pain syndrome, PN and CNS diseases, can also influence DED. Although most studies on the association of DED with psychiatric or neurological disorders were of crosssectional nature and failed to show causal relationship, the close alignment between DED and various psychiatric or neurological disorders suggests the presence of shared pathophysiological mechanisms or reciprocal influence. Repeated or severe ocular surface damage can induce peripheral and central sensitization, which leads to persistent neuropathic ocular pain. ${ }^{2,56}$

Attention should be paid to DED patients, particularly to those with inconsistent dry eye symptoms and signs and poor response to conventional treatment, for associated psychiatric or neurological disorders, and an integrated treatment approach could be helpful for the patients. Further research is necessary for the elucidation of the mechanisms underlying the association of DED with psychiatric or neurological disorders and development of treatment methods for DED associated with these conditions.

\section{Acknowledgment}

This study was supported by 2017 Research Grant from Kangwon National University.

\section{Disclosure}

The authors report no conflicts of interest in this work.

\section{References}

1. Smith JA, Albenz J, Begley C, et al. The epidemiology of dry eye disease: report of the Epidemiology Subcommittee of the International Dry Eye WorkShop (2007). Ocul Surf. 2007;5(2):93-107.

2. Kalangara JP, Galor A, Levitt RC, Felix ER, Alegret R, Sarantopoulos CD. Burning eye syndrome: do neuropathic pain mechanisms underlie chronic dry eye? Pain Med. 2016;17(4):746-755.

3. Amparo F, Hamrah P, Schaumberg DA, Dana R. The value of tear osmolarity as a metric in evaluating the response to dry eye therapy in the clinic and in clinical trials. Am J Ophthalmol. 2014;157(4):915-916.

4. Schein OD, Munoz B, Tielsch JM, Bandeen-Roche K, West S. Prevalence of dry eye among the elderly. Am J Ophthalmol. 1997;124(6): 723-728.
5. Galor A, Feuer W, Lee DJ, et al. Prevalence and risk factors of dry eye syndrome in a United States veterans affairs population. $\mathrm{Am} J$ Ophthalmol. 2011;152(3):377-384.e2.

6. Galor A, Feuer W, Lee DJ, et al. Depression, post-traumatic stress disorder, and dry eye syndrome: a study utilizing the national United States Veterans Affairs administrative database. Am J Ophthalmol. 2012; 154(2):340-346.e2.

7. Schaumberg DA, Dana R, Buring JE, Sullivan DA. Prevalence of dry eye disease among US men: estimates from the Physicians' Health Studies. Arch Ophthalmol. 2009;127(6):763-768.

8. Schaumberg DA, Sullivan DA, Buring JE, Dana MR. Prevalence of dry eye syndrome among US women. Am J Ophthalmol. 2003;136(2): 318-326.

9. Han SB, Hyon JY, Woo SJ, Lee JJ, Kim TH, Kim KW. Prevalence of dry eye disease in an elderly Korean population. Arch Ophthalmol. 2011; 129(5):633-638.

10. Yu J, Asche CV, Fairchild CJ. The economic burden of dry eye disease in the United States: a decision tree analysis. Cornea. 2011;30(4): 379-387.

11. Lemp MA. The definition and classification of dry eye disease: report of the Definition and Classification Subcommittee of the International Dry Eye WorkShop (2007). Ocul Surf. 2007;5(2):75-92.

12. Galor A, Felix ER, Feuer W, et al. Dry eye symptoms align more closely to non-ocular conditions than to tear film parameters. Br J Ophthalmol. 2015;99(8):1126-1129.

13. Galor A, Levitt RC, Felix ER, Martin ER, Sarantopoulos CD. Neuropathic ocular pain: an important yet underevaluated feature of dry eye. Eye (Lond). 2015;29(3):301-312.

14. Sullivan BD, Crews LA, Messmer EM, et al. Correlations between commonly used objective signs and symptoms for the diagnosis of dry eye disease: clinical implications. Acta Ophthalmol. 2014;92(2): 161-166.

15. Schein OD, Tielsch JM, Munoz B, Bandeen-Roche K, West S. Relation between signs and symptoms of dry eye in the elderly. A population-based perspective. Ophthalmology. 1997;104(9): 1395-1401.

16. Nichols KK, Nichols JJ, Mitchell GL. The lack of association between signs and symptoms in patients with dry eye disease. Cornea. 2004;23(8):762-770.

17. Vehof J, Sillevis Smitt-Kamminga N, Nibourg SA, Hammond CJ. Predictors of discordance between symptoms and signs in dry eye disease. Ophthalmology. 2017;124(3):280-286.

18. Galor A, Seiden BE, Park JJ, et al. The association of dry eye symptom severity and comorbid insomnia in US veterans. Eye Contact Lens. Epub 2017 Jan 6.

19. Kim KW, Han SB, Han ER, et al. Association between depression and dry eye disease in an elderly population. Invest Ophthalmol Vis Sci. 2011;52(11):7954-7958.

20. Kalangara JP, Galor A, Levitt RC, et al. Characteristics of ocular pain complaints in patients with idiopathic dry eye symptoms. Eye Contact Lens. Epub 2016 Feb 29.

21. McMonnies CW. The potential role of neuropathic mechanisms in dry eye syndromes. J Optom. 2017;10(1):5-13.

22. Shtein RM, Harper DE, Pallazola V, et al. Discordant dry eye disease (An American Ophthalmological Society Thesis). Trans Am Ophthalmol Soc. 2016;114:T4

23. van der Vaart R, Weaver MA, Lefebvre C, Davis RM. The association between dry eye disease and depression and anxiety in a large population-based study. Am J Ophthalmol. 2015;159(3):470-474.

24. Labbe A, Wang YX, Jie Y, Baudouin C, Jonas JB, Xu L. Dry eye disease, dry eye symptoms and depression: the Beijing Eye Study. Br J Ophthalmol. 2013;97(11):1399-1403.

25. Na KS, Han K, Park YG, Na C, Joo CK. Depression, stress, quality of life, and dry eye disease in Korean women: a population-based study. Cornea. 2015;34(7):733-738.

26. Yilmaz U, Gokler ME, Unsal A. Dry eye disease and depression-anxietystress: a hospital-based case control study in Turkey. PakJ Med Sci. 2015; 31(3):626-631. 
27. Ong ES, Alghamdi YA, Levitt RC, et al. Longitudinal examination of frequency of and risk factors for severe dry eye symptoms in US veterans. JAMA Ophthalmol. Epub 2016 Dec 22.

28. Szakats I, Sebestyen M, Nemeth J, Birkás E, Purebl G. The role of health anxiety and depressive symptoms in dry eye disease. Curr Eye Res. 2016;41(8):1044-1049.

29. Hallak JA, Tibrewal S, Jain S. Depressive symptoms in patients with dry eye disease: a case-control study using the beck depression inventory. Cornea. 2015;34(12):1545-1550.

30. Nepp J. Psychosomatic aspects of dry eye syndrome. Ophthalmologe. 2016;113(2):111-119.

31. Wan KH, Chen LJ, Young AL. Depression and anxiety in dry eye disease: a systematic review and meta-analysis. Eye (Lond). 2016; 30(12):1558-1567.

32. Zhang Y, Lin T, Jiang A, Zhao N, Gong L. Vision-related quality of life and psychological status in Chinese women with Sjogren's syndrome dry eye: a case-control study. BMC Womens Health. 2016;16(1):75.

33. Miljanovic B, Trivedi KA, Dana MR, Gilbard JP, Buring JE, Schaumberg DA. Relation between dietary n-3 and n- 6 fatty acids and clinically diagnosed dry eye syndrome in women. Am J Clin Nutr. 2005;82(4):887-893.

34. Lutgendorf SK, Garand L, Buckwalter KC, Reimer TT, Hong SY, Lubaroff DM. Life stress, mood disturbance, and elevated interleukin-6 in healthy older women. J Gerontol A Biol Sci Med Sci. 1999;54(9):M434-M439.

35. Amparo F, Schaumberg DA, Dana R. Comparison of two questionnaires for dry eye symptom assessment: the ocular surface disease index and the symptom assessment in dry eye. Ophthalmology. 2015 122(7):1498-1503.

36. Liyue H, Chiang PP, Sung SC, Tong L. Dry eye-related visual blurring and irritative symptoms and their association with depression and anxiety in eye clinic patients. Curr Eye Res. 2016;41(5):590-599.

37. Li M, Gong L, Chapin WJ, Zhu M. Assessment of vision-related quality of life in dry eye patients. Invest Ophthalmol Vis Sci. 2012;53(9): 5722-5727.

38. Hallak JA, Tibrewal S, Mohindra N, Gao X, Jain S. Single nucleotide polymorphisms in the BDNF, VDR, and DNASE 1 genes in dry eye disease patients: a case-control study. Invest Ophthalmol Vis Sci. 2015; 56(10):5990-5996.

39. Ayaki M, Kawashima M, Negishi K, Tsubota K. High prevalence of sleep and mood disorders in dry eye patients: survey of 1,000 eye clinic visitors. Neuropsychiatr Dis Treat. 2015;11:889-894.

40. Ayaki M, Toda I, Tachi N, Negishi K, Tsubota K. Preliminary report of improved sleep quality in patients with dry eye disease after initiation of topical therapy. Neuropsychiatr Dis Treat. 2016;12:329-337.

41. Priori R, Minniti A, Antonazzo B, Fusconi M, Valesini G, Curcio G. Sleep quality in patients with primary Sjogren's syndrome. Clin Exp Rheumatol. 2016;34(3):373-379.

42. Shen CC, Yang AC, Kuo BI, Tsai SJ. Risk of psychiatric disorders following primary sjogren syndrome: a nationwide population-based retrospective cohort study. J Rheumatol. 2015;42(7):1203-1208.

43. Lee W, Lim SS, Won JU, et al. The association between sleep duration and dry eye syndrome among Korean adults. Sleep Med. 2015;16(11): 1327-1331.

44. Lee YB, Koh JW, Hyon JY, Wee WR, Kim JJ, Shin YJ. Sleep deprivation reduces tear secretion and impairs the tear film. Invest Ophthalmol Vis Sci. 2014;55(6):3525-3531.

45. Acan D, Kurtgoz P. Influence of selective serotonin reuptake inhibitors on ocular surface. Clin Exp Optom. 2017;100(1):83-86.

46. Wong J, Lan W, Ong LM, Tong L. Non-hormonal systemic medications and dry eye. Ocul Surf. 2011;9(4):212-226.

47. Wilson K, Mottram P. A comparison of side effects of selective serotonin reuptake inhibitors and tricyclic antidepressants in older depressed patients: a meta-analysis. Int J Geriatr Psychiatry. 2004;19(8): 754-762.

48. Ghaffariyeh A, Chamacham T. Tricyclic antidepressants: potential therapeutic alternatives for treatment of dry eye symptoms after LASIK. J Refract Surg. 2008;24(8):770-771; author reply 1-2.
49. Fernandez CA, Galor A, Arheart KL, et al. Dry eye syndrome, posttraumatic stress disorder, and depression in an older male veteran population. Invest Ophthalmol Vis Sci. 2013;54(5):3666-3672.

50. Wen $\mathrm{W}, \mathrm{Wu} \mathrm{Y}, \mathrm{Chen} \mathrm{Y}$, et al. Dry eye disease in patients with depressive and anxiety disorders in Shanghai. Cornea. 2012;31(6):686-692.

51. Kocer E, Kocer A, Ozsutcu M, Dursun AE, Krpnar I. Dry eye related to commonly used new antidepressants. J Clin Psychopharmacol. 2015; 35(4):411-413.

52. Dibajnia P, Mohammadinia M, Moghadasin M, Amiri MA. Tear film break-up time in bipolar disorder. Iran J Psychiatry. 2012;7(4): 191-193.

53. Jensen TS, Baron R, Haanpaa M, et al. A new definition of neuropathic pain. Pain. 2011;152(10):2204-2205.

54. Ro LS, Chang KH. Neuropathic pain: mechanisms and treatments. Chang Gung Med J. 2005;28(9):597-605.

55. Latremoliere A, Woolf CJ. Central sensitization: a generator of pain hypersensitivity by central neural plasticity. J Pain. 2009;10(9): 895-926.

56. Goyal S, Hamrah P. Understanding neuropathic corneal pain - gaps and current therapeutic approaches. Semin Ophthalmol. 2016; 31(1-2):59-70.

57. Levitt AE, Galor A, Weiss JS, et al. Chronic dry eye symptoms after LASIK: parallels and lessons to be learned from other persistent postoperative pain disorders. Mol Pain. 2015;11:21

58. Chao C, Golebiowski B, Stapleton F. The role of corneal innervation in LASIK-induced neuropathic dry eye. Ocul Surf. 2014;12(1):32-45.

59. Oswald DJ, Lee A, Trinidad M, et al. Communication between corneal epithelial cells and trigeminal neurons is facilitated by purinergic (P2) and glutamatergic receptors. PLoS One. 2012;7(9):e44574.

60. Galor A, Zlotcavitch L, Walter SD, et al. Dry eye symptom severity and persistence are associated with symptoms of neuropathic pain. Br J Ophthalmol. 2015;99(5):665-668.

61. Spierer O, Felix ER, McClellan AL, et al. Corneal mechanical thresholds negatively associate with dry eye and ocular pain symptoms. Invest Ophthalmol Vis Sci. 2016;57(2):617-625.

62. Galor A, Batawi H, Felix ER, et al. Incomplete response to artificial tears is associated with features of neuropathic ocular pain. Br JOphthalmol. 2016;100(6):745-749.

63. Galor A, Levitt RC, McManus KT, et al. Assessment of somatosensory function in patients with idiopathic dry eye symptoms. JAMA Ophthalmol. 2016;134(11):1290-1298.

64. Crane AM, Feuer W, Felix ER, et al. Evidence of central sensitisation in those with dry eye symptoms and neuropathic-like ocular pain complaints: incomplete response to topical anaesthesia and generalised heightened sensitivity to evoked pain. Br J Ophthalmol. Epub 2017 Jan 18.

65. Crane AM, Levitt RC, Felix ER, Sarantopoulos KD, McClellan AL, Galor A. Patients with more severe symptoms of neuropathic ocular pain report more frequent and severe chronic overlapping pain conditions and psychiatric disease. Br J Ophthalmol. 2017;101(2):227-231.

66. Vehof J, Zavos HM, Lachance G, Hammond CJ, Williams FM. Shared genetic factors underlie chronic pain syndromes. Pain. 2014; 155(8):1562-1568.

67. Vehof J,Kozareva D, Hysi PG, etal. Relationship between dry eye symptoms and pain sensitivity. JAMA Ophthalmol. 2013;131(10):1304-1308.

68. Achtsidis V, Eleftheriadou I, Kozanidou E, et al. Dry eye syndrome in subjects with diabetes and association with neuropathy. Diabetes Care. 2014;37(10):e210-e211

69. Dehghani C, Pritchard N, Edwards K, et al. Natural history of corneal nerve morphology in mild neuropathy associated with type 1 diabetes: development of a potential measure of diabetic peripheral neuropathy. Invest Ophthalmol Vis Sci. 2014;55(12):7982-7990.

70. Misra SL, Patel DV, McGhee CN, et al. Peripheral neuropathy and tear film dysfunction in type 1 diabetes mellitus. J Diabetes Res. 2014; 2014:848659.

71. DeMill DL, Hussain M, Pop-Busui R, Shtein RM. Ocular surface disease in patients with diabetic peripheral neuropathy. Br J Ophthalmol. 2016; 100(7):924-928. 
72. van Bijsterveld OP, Kruize AA, Bleys RL. Central nervous system mechanisms in Sjogren's syndrome. Br J Ophthalmol. 2003;87(2): 128-130.

73. Rosenthal P, Borsook D. Ocular neuropathic pain. Br JOphthalmol.2016; 100(1):128-134.

74. Goransson LG, Herigstad A, Tjensvoll AB, Harboe E, Mellgren SI, Omdal R. Peripheral neuropathy in primary sjögren syndrome: a population-based study. Arch Neurol. 2006;63(11):1612-1615.

75. Han SB, Hyon JY, Wee WR, Lee JH, Lee YJ, Yun PY. Reduced corneal sensitivity in patients with primary Sjogren's syndrome. Acta Ophthalmol. 2010;88(7):e277-e278.

76. Villani E, Galimberti D, Viola F, et al. The cornea in Sjögren's syndrome: an in vivo confocal study. Invest Ophthalmol Vis Sci. 2007;48(5): 2017-2022.

77. Morreale M, Marchione P, Giacomini P, et al. Neurological involvement in primary Sjogren syndrome: a focus on central nervous system. PLoS One. 2014;9(1):e84605.

78. Kinard KI, Smith AG, Singleton JR, et al. Chronic migraine is associated with reduced corneal nerve fiber density and symptoms of dry eye. Headache. 2015;55(4):543-549.

79. Yang S, Kim W, Kim HS, Na KS; Epidemiologic Survey Committee of the Korean Ophthalmologic Society. Association between migraine and dry eye disease: a nationwide population-based study. Curr Eye Res. 1-5. Epub 2017 Jan 27.

80. Borsook D, Rosenthal P. Chronic (neuropathic) corneal pain and blepharospasm: five case reports. Pain. 2011;152(10):2427-2431.

81. Kroenke K, Wu JW, Bair MJ, Krebs EE, Damush TM, Tu W. Reciprocal relationship between pain and depression: a 12-month longitudinal analysis in primary care. J Pain. 2011;12(9):964-973.

82. McGreevy K, Bottros MM, Raja SN. Preventing chronic pain following acute pain: risk factors, preventive strategies, and their efficacy. Eur J Pain Suppl. 2011;5(2):365-372.
83. Kawano T, Zoga V, Gemes G, et al. Suppressed Ca2+/CaM/CaMKIIdependent K(ATP) channel activity in primary afferent neurons mediates hyperalgesia after axotomy. Proc Natl Acad Sci U S A. 2009;106(21): 8725-8730.

84. Zollner C, Mousa S, Klinger A, Förster M, Schäfer M. Topical fentanyl in a randomized, double-blind study in patients with corneal damage. Clin J Pain. 2008;24(8):690-696.

85. Wenk HN, Nannenga MN, Honda CN. Effect of morphine sulphate eye drops on hyperalgesia in the rat cornea. Pain. 2003;105(3):455-465.

86. Attal N, Cruccu G, Baron R, et al. EFNS guidelines on the pharmacological treatment of neuropathic pain: 2010 revision. Eur JNeurol. 2010; 17(9):1113-e88.

87. Wu YQ, Dang RL, Tang MM, et al. Long chain omega-3 polyunsaturated fatty acid supplementation alleviates doxorubicin-induced depressive-like behaviors and neurotoxicity in rats: involvement of oxidative stress and neuroinflammation. Nutrients. 2016;8(4):243.

88. Mal'tsev DS, Kudryashova EV. Cyanocobalamin-containing lubricant for topical therapy of LASIK-associated dry eye. Vestn Oftalmol. 2016; 132(1):68-75

89. Shetty R, Deshpande K, Ghosh A, Sethu S. Management of ocular neuropathic pain with vitamin B12 supplements: a case report. Cornea. 2015;34(10):1324-1325.

90. Hayek SM, Sweet JA, Miller JP, Sayegh RR. Successful management of corneal neuropathic pain with intrathecal targeted drug delivery. Pain Med. 2016;17(7):1302-1307.

91. Sayegh RR, Sweet JA, Miller JP, Hayek SM. Electrical stimulation of the trigeminal ganglion and intrathecal drug delivery systems for the management of corneal neuropathic pain. Cornea. 2016;35(4):576-577.

92. Theophanous C, Jacobs DS, Hamrah P. Corneal neuralgia after LASIK. Optom Vis Sci. 2015;92(9):e233-e240.
Clinical Interventions in Aging

\section{Publish your work in this journal}

Clinical Interventions in Aging is an international, peer-reviewed journal focusing on evidence-based reports on the value or lack thereof of treatments intended to prevent or delay the onset of maladaptive correlates of aging in human beings. This journal is indexed on PubMed Central, MedLine,
Dovepress

CAS, Scopus and the Elsevier Bibliographic databases. The manuscript management system is completely online and includes a very quick and fair peer-review system, which is all easy to use. Visit http://www.dovepress. com/testimonials.php to read real quotes from published authors. 